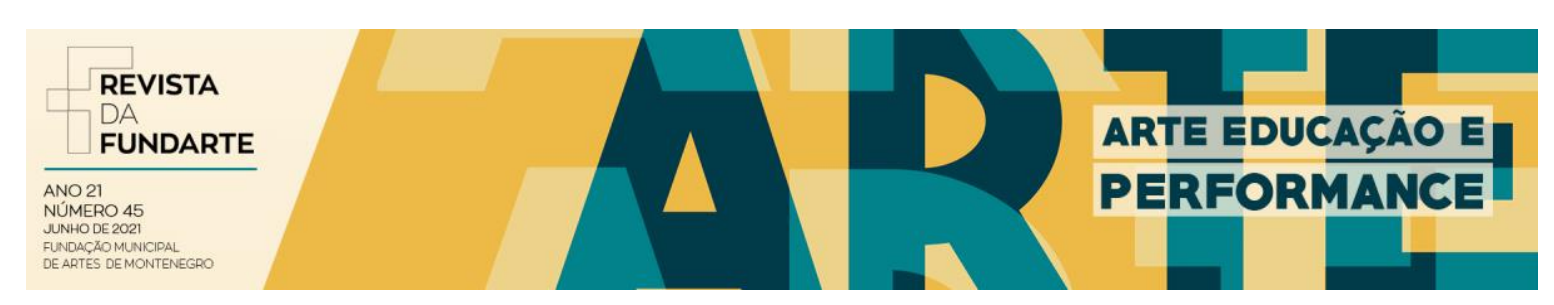

DANÇA NO CONTEXTO ESCOLAR: ANTIGAS E NOVAS QUESTÕES

\author{
Gustavo De Oliveira Duarte \\ Daniela Llopart Castro \\ Daniela Grieco Nascimento e Silva
}

DOI: $10.19179 / 2319-0868 / 782$

DUARTE, Gustavo De Oliveira; CASTRO, Daniela Llopart; SILVA, Daniela Grieco Nascimento e. Dança no contexto escolar: antigas e novas questões. Revista da FUNDARTE. Montenegro, p.01-13, ano $21, n^{\circ} 45$, junho de 2021.

Disponível em: http://.seer.fundarte.rs.gov.br/index.php/revistadafundarte/index> 30 de junho de 2021. 


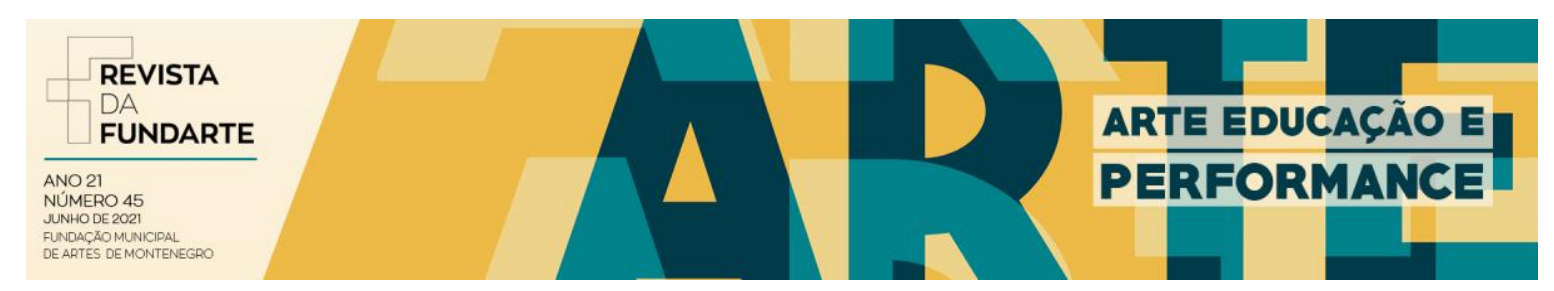

\title{
DANÇA NO CONTEXTO ESCOLAR: ANTIGAS E NOVAS QUESTÕES
}

\author{
Gustavo De Oliveira Duarte ${ }^{1}$ \\ Daniela Llopart Castro² \\ Daniela Grieco Nascimento e Silva ${ }^{3}$
}

\begin{abstract}
Resumo: O texto aborda o ensino de Dança na Escola a partir do Programa Institucional de Bolsas de Iniciação à Docência (PIBID) realizados na Universidade Federal de Pelotas (UFPel/RS) e na Universidade Federal de Santa Maria (UFSM/RS). Problematizamos experiências didáticometodológicas a partir de um trabalho de intervenção na área de Artes das escolas envolvidas. Os resultados apontaram significativa relevância tanto na formação inicial dos pibidianos quanto na formação continuada dos professores das Escolas. Temáticas transversais articularam os conteúdos trabalhados com a prática social. A Dança como área de conhecimento na Escola pode contribuir na formação estética da comunidade escolar e no desenvolvimento estético-crítico do educador.
\end{abstract}

Palavras-chave: Dança; Escola; Currículo.

\section{DANCE IN THE SCHOOL CONTEXT: OLD AND NEW ISSUES}

\begin{abstract}
The text addresses the teaching of Dance in School from the Institutional Program for Teaching Initiation Scholarships (PIBID) held at the Federal University of Pelotas (UFPel / RS) and at the Federal University of Santa Maria (UFSM / RS). We problematize didactic-methodological experiences from an intervention work in the Arts area of the schools involved. The results showed significant relevance both in the initial training of the pibidians and in the continuing training of the teachers of the Schools. Cross-cutting themes articulated the contents worked with social practice. Dance as an area of knowledge in the School can contribute to the aesthetic formation of the school community and to the educator's aesthetic-critical development.
\end{abstract}

Keywords: Dance; School; Curriculum.

\section{Introdução}

Este texto trata a Dança como área de conhecimento, ou seja, compreende-a como uma linguagem artística e educativa ao mesmo tempo, isto implica dizer que aqui não iremos tratar de outros objetivos aos quais a Dança se propõe como recreação, entretenimento ou competição. Neste sentido procuramos levantar questões e discutir sobre o ensino de Dança no espaço escolar, seja no currículo ou fora dele - seus limites e possibilidades. Faz-se necessário, nesta perspectiva,

${ }^{1}$ Curso de Dança, Licenciatura, do Centro de Educação Física e Desportos da Universidade Federal de Santa Maria, RS. Curso de Dança - CEFD/UFSM/RS.

2 Universidade Federal de Pelotas (UFPel). Profa Dda. Adjunta do Curso de Dança do Centro de Artes da UFPel/RS.

${ }^{3}$ Royale Escola de Dança e Integração Social. Dra. em Educação, Pós-Doutoranda no Centro de Educação Física e Desportos da UFSM/RS. Bailarina e Professora de Ballet.

DUARTE, Gustavo De Oliveira; CASTRO, Daniela Llopart; SILVA, Daniela Grieco Nascimento e. Dança no contexto escolar: antigas e novas questões. Revista da FUNDARTE. Montenegro, p.01-13, ano 21 , no 45, junho de 2021.

Disponível em: http://.seer.fundarte.rs.gov.br/index.php/revistadafundarte/index> 30 de junho de 2021. 


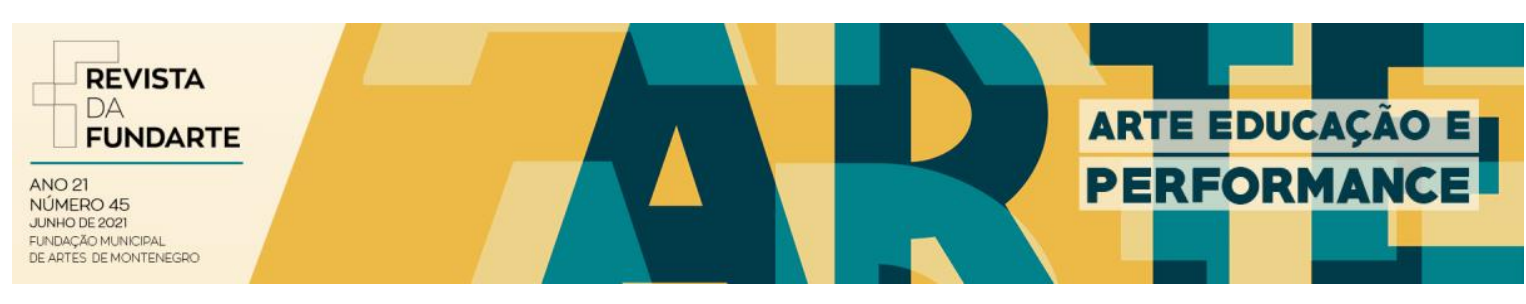

problematizar antigas e novas questões relevantes sobre o tema, dialogando a partir de concepções de Corpo, de Educação e do momento atual em que vivemos, a chamada Contemporaneidade. A partir desta contextualização inicial destacamos, mais adiante, algumas possibilidades didático-metodológicas para o ensino de Dança no contexto escolar a partir experiências no PIBID (Programa Institucional de Bolsas de Iniciação à Docência) no Curso de Dança, Licenciatura, na Universidade Federal de Pelotas (UFPel), na Universidade Federal de Santa Maria (UFSM), ambas cidades do interior do estado do Rio Grande do Sul.

Inúmeras questões envolvem o complexo e fascinante universo da Dança tais como liberdade de expressão, contestação e crítica social, diferentes abordagens de criação e composição coreográfica, entrega, disponibilidade e amor incondicional à Arte; (re) montagens de repertórios de Dança internacionais, a dificuldade e a luta por patrocínios, por editais e o difícil acesso às leis da área da Cultura ou da Educação, para a viabilização de espetáculos das Companhias brasileiras, o "glamour" dos palcos e dos aplausos (ou "vaias") do público, as influências das famílias de bailarinos, a preocupação com o "mercado" de trabalho, com a vida de artista, os rigores "da técnica", o "ego" de bailarinos/as e dos diretores - a maioria homens (é claro!), entre outros. Sim, nenhuma novidade até aí, mas a questão que pretendemos refletir é que o ensino de Dança no contexto escolar, além destas, exige outras questões significativas que precisamos, como educadores, analisar e propor um diálogo possível, produtivo, atento, portanto, sensíveis. Tarefa nada fácil e de uma importância e complexidade enormes.

A introdução da Dança na escola passa historicamente pelo desenvolvimento da Dança Moderna, uma vez que Rudolf Laban foi um dos primeiros pensadores a defender a importância da Dança como expressão da subjetividade e de autoconhecimento das potencialidades do movimento, com suas diferentes qualidades e múltiplas possibilidades de combinação. Desde a primeira edição do livro de Laban, Dança Educativa Moderna, em 1948, já existe a ideia de que a Dança não deve estar presente na Escola como reprodução de movimentos codificados e rígidos, mas sim, como um processo de descoberta e experimentação, que não ignore a sensibilidade, a capacidade de (re) encontrar novos modos de ser,

DUARTE, Gustavo De Oliveira; CASTRO, Daniela Llopart; SILVA, Daniela Grieco Nascimento e. Dança no contexto escolar: antigas e novas questões. Revista da FUNDARTE. Montenegro, p.01-13, ano 21, no 45, junho de 2021.

Disponível em: http://.seer.fundarte.rs.gov.br/index.php/revistadafundarte/index> 30 de junho de 2021. 


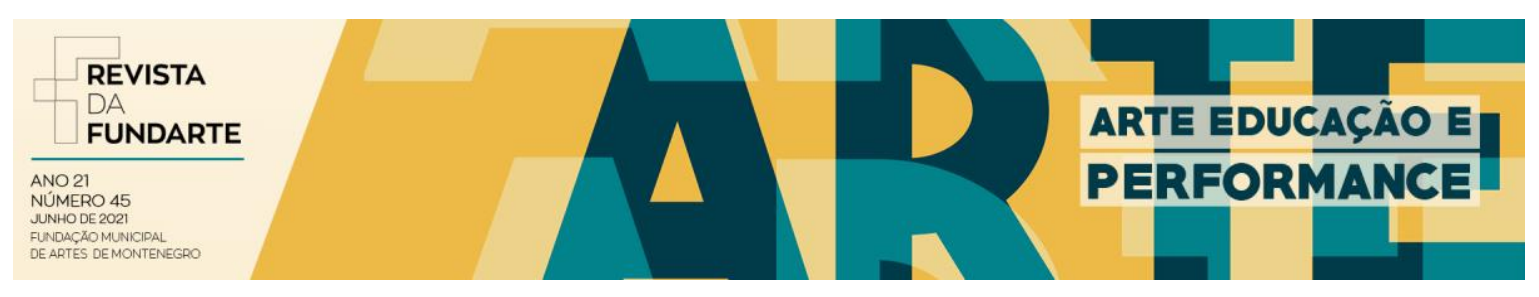

permitindo que o professor de Dança, possa permitir-se a tarefa de produzir arte com os alunos ou grupo de alunos (ICLE, 2012).

Neste sentido, é interessante contextualizar como o conhecimento artístico, enquanto área de estudo das Artes foi incluída no currículo escolar, nas escolas brasileiras em 1971, pela Lei de Diretrizes e bases da Educação Nacional (LDB №5692/1971), sob o nome de Educação Artística, sendo considerada como uma "atividade educativa" e não como uma disciplina obrigatória. Dentre o conjunto das atividades artísticas, a área da Dança foi a menos desenvolvida e incentivada em relação às demais.

Com a Lei de Diretrizes e Bases (LDB) № 9.394/1996, a Arte passou a ser considerada obrigatória na educação brasileira, passando a se constituir como componente curricular nos diversos níveis da Educação Básica, revogando a anterior, onde foi fundamental a contribuição das ideias de Ana Mae Barbosa (2010) tendo como premissa básica a integração do fazer artístico, a apreciação da obra de arte (fruição) e sua contextualização histórica, difundida pelas indicações da "Proposta Triangular para o Ensino da Arte" (1994), onde prevalecia o ensino das Artes Visuais.

Nesse seguimento, surgem os Parâmetros Curriculares Nacionais da Área de Arte de 1997, revogando-se as disposições anteriores e a Arte é considerada disciplina obrigatória na educação básica. Assim, ampliaram-se o pensar artístico e a percepção estética, de modo que o aluno desenvolva seus modos próprios de sensibilidade, percepção e apreciação, produzidas por eles, pelos colegas, e nas diferentes culturas. Marques (1980) compreende como fundamental, as imbricações entre Arte e Educação, no sentido de aprofundar e ressignificar a Dança como conhecimento na Escola, partindo da experimentação de movimento como forma individual e coletivo, complementado por Duarte Jr (1994) que a privilegia como a educação estética.

\section{Dança: Entre festas de calendário e a cultura da esportivização}

A partir de nossas experiências junto ao contexto escolar, no próprio ensino de Dança para crianças e adolescentes e, também, na supervisão de Estágio Curricular Supervisionado nas cidades de Porto Alegre, Pelotas e Santa Maria, além 


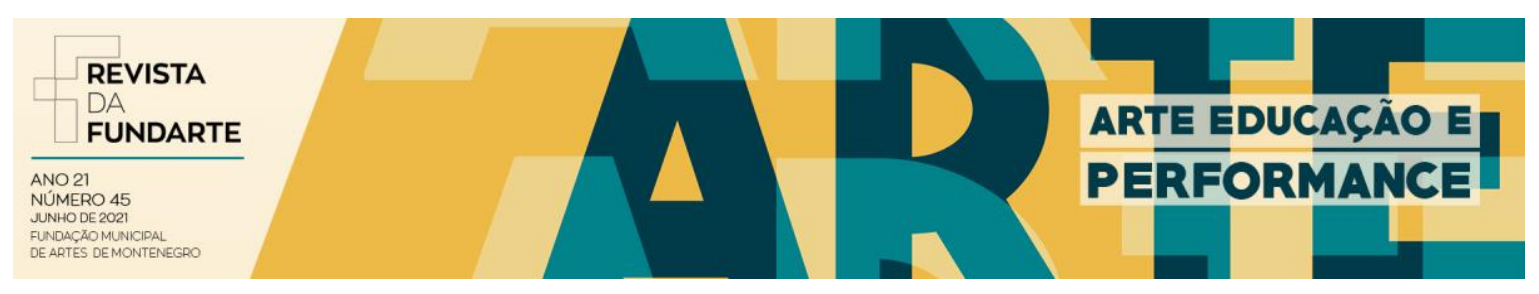

de vários estudos (MIRANDA, 1994; PACHECO, 2006; MARQUES, 1999) apontam que, muitas vezes, a presença da Dança na Escola acaba se resumindo somente a cumprir objetivos recreativos, para "relaxar e liberar o estresse" ou para ilustrar datas tradicionais dos calendários escolares. Enfim, como a "cereja do bolo"! Ainda que cada região brasileira apresente suas riquezas, características e contextos singulares, a Dança como "espetáculo" com data marcada ainda é muito significativa e, de certa forma, o seu ensino, artisticamente falando, raso e/ou superficial. Sob este aspecto gostaria de destacar dois caminhos possíveis para tentar superar e auxiliar na transformação de tal situação.

O primeiro caminho seria juntar-se, aliar-se ao "sistema", ou seja, não negar ou fugir de dançar e criar coreografias, a partir de estudos e pesquisas de qualidade, para as estas datas comemorativas, mas, sobretudo, buscar ampliar/subverter/mediar/negociar/chocar/dialogar com os alunos sobre o por quê, para quê e, principalmente, como dançar tais datas, de maneira contextualizada e reflexiva. Esse é o diferencial da área de Arte e da Educação. Por exemplo, no "Dia das Mães e/ou "Dia dos Pais" (poderia ser o Dia das Famílias ou o Dia da Afetividade...), poder-se-ia problematizar as diferentes leituras de mulheres e homens a partir do contexto dos próprios alunos, de suas famílias, seus jeitos, seus costumes, seus gostos, buscando sentidos e significados para a ação, para a construção das cenas dançantes (DUARTE, 2011), das composições a serem dançadas.

Cada turma, ou a união de duas ou mais, poderia ficar responsável por dançar/apresentar uma ou mais datas do calendário escolar, não necessitando todos/as dançarem tudo, sempre, pois aí pode acabar banalizando. Neste caminho o processo criativo, de investigação corporal sobre o tema/eixo a ser dançado poderia ser mais bem explorado, envolvendo e despertando maior interesse dos alunos na escola, para além dos modismos que eles/as trazem, as chamadas "dancinhas" da moda, do circuito comercial.

Outro desdobramento desta questão seria cada Escola, de acordo com seu contexto e de seu planejamento bimestral, semestral, anual, criar outras datas comemorativas para além, ou substituindo, as datas tradicionalmente consagradas 


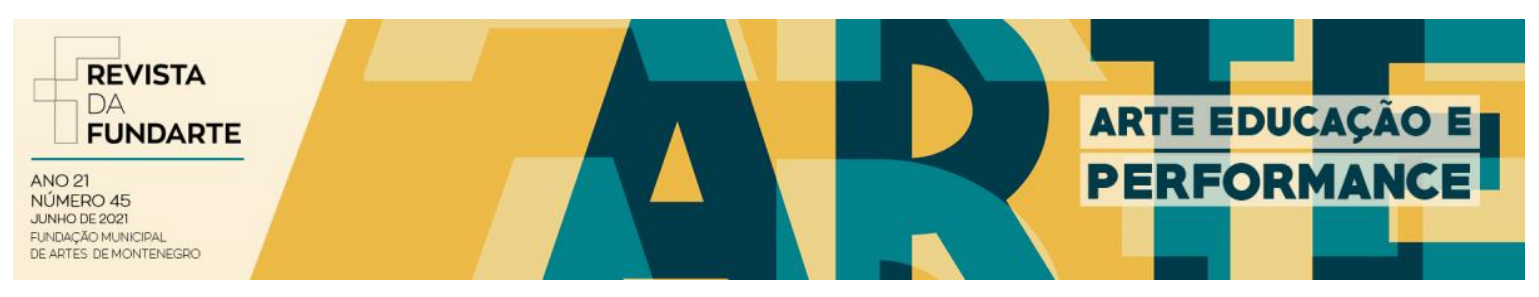

como, por exemplo, dia da água, da solidariedade, dia do idoso (da avó ou do avô), dia dos animais, da adoção, dia do abraço, dia do cinema, dia da diversidade, da inclusão, entre outros. Neste primeiro caminho que apontamos, a improvisação (HASELBACH, 1998; FEIJÓ, 1996; DUARTE, 2003) seria a "base", a técnica, para planejar e compor este trabalho artístico de Dança na Escola, por mais redundante que isto possa aparecer.

Neste sentido, cada escola, ou professor/a de Dança ou de Artes (antiga Educação Artística), juntamente com os alunos e com as singularidades do contexto, elegerem uma técnica codificada para pesquisar, para aprofundar, para "fazer aula", para chamar outros bailarinos ou professores da dança escolhida, para aí sim, estudar e aprofundar seus estudos nesta técnica: Danças de Salão, ou Danças de Matriz Africana ou Danças Urbanas, por exemplo. Essa ação, deliberada com e a partir da realidade dos alunos poderia propiciar uma maior qualidade e legitimar 0 espaço, o território da dança na Escola, se aproximando de uma "Escola-palco" (BARRETO, 2005).

Algumas vezes, o/a professor/a da escola fica preso/a a uma ilusão de que precisa dar conta de tudo, saber de tudo e acaba ficando sobrecarregado em seus planejamentos e pesquisas. Mas, ao contrário, de uma maneira colaborativa, o/a docente pode e deve propor um diálogo mais profundo com seus alunos, partindo de seus desejos, resistências e possibilidades. Construir e compartilhar um roteiro de ação flexível para e com os alunos, que tenha sentido para cada um e para a turma como um todo. Afinal, em Arte e, especificamente, em Dança, cada turma é uma turma, os corpos são histórias vivas, ora mais visíveis, ora mais escondidas. É preciso provocar, jogar, negociar, isto é, trazer o aluno para perto de nós, professores, dividir a responsabilidade de criar, pesquisar, dançar. Para além de nossos planejamentos e estudos, é preciso considerar que são os alunos que nos dão "pistas" de onde e por quais caminhos desenvolvem um trabalho criativo, sensível, artístico.

Um segundo caminho de possibilidade no sentido de enfrentar a questão que está muito associada à vivência e ao ensino de Dança na Escola é certa tendência de compreender e associar a Dança, exclusivamente, a uma dimensão competitiva,

DUARTE, Gustavo De Oliveira; CASTRO, Daniela Llopart; SILVA, Daniela Grieco Nascimento e. Dança no contexto escolar: antigas e novas questões. Revista da FUNDARTE. Montenegro, p.01-13, ano 21 , no 45, junho de 2021.

Disponível em: http://.seer.fundarte.rs.gov.br/index.php/revistadafundarte/index> 30 de junho de 2021. 


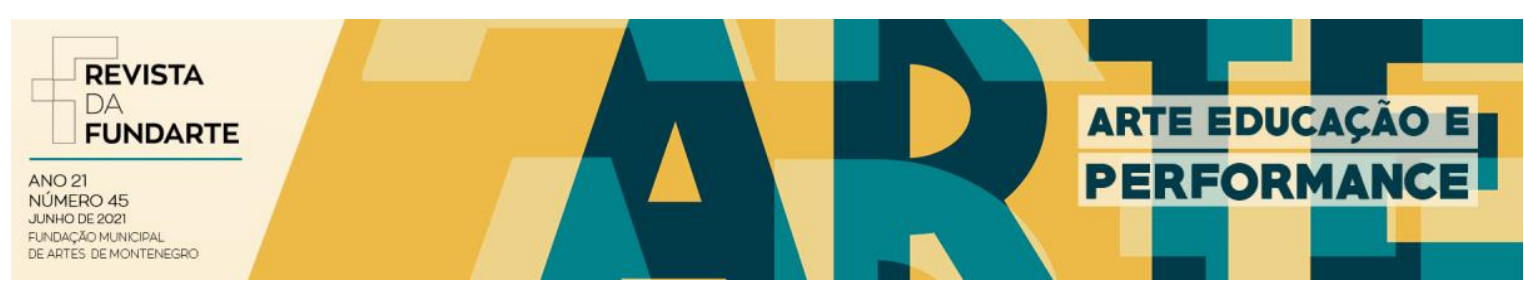

isto é, voltada para ganhar, vencer e, até mesmo, desprezar/humilhar o outro. Esta compreensão de Dança, advinda de festivais e competições, de certa forma "contaminou", significativamente, o ambiente escolar, caracterizando a dança como uma ação esportivizada, onde o mostrar, o superar e o fazer passos e gestos que ninguém, ou a maioria, faz é o que está em jogo. Esta compreensão é facilmente encontrada, tanto entre alunos/as, quanto aos professores/as que trabalham na Escola, sobretudo nas áreas de Educação Física - área de conhecimento que trabalha a Dança (como conteúdo) há mais tempo, formalmente e, na maioria das vezes sem uma formação aprofundada, se comparada à área da Arte.

Neste sentido, vale destacar que o ensino e a vivência da Dança não é um privilégio somente da área da Arte, muitos/as professores de Educação Física, de Pedagogia e/ou Teatro, ainda que com visões da Dança como uma "ferramenta" para o ensino de outros saberes, têm se mostrado sensíveis ao potencial educativo que a Dança oferece e desenvolvem ações neste sentido na Escola. Devemos compreender que não se faz produtivo combater ou criticar, simplesmente, tais ações. Provavelmente isto irá continuar, cada professor tem certa autonomia de trabalhar o corpo em movimento, ainda que com outro objetivo, muitas vezes camuflado de artístico.

Nossa aposta, a partir de nossas andanças por diferentes contextos escolares é de não criticar os demais colegas, demarcando um discurso do tipo "a dança é nossa! " (até porque a dança muito provavelmente seguirá sendo desenvolvida em outras áreas); mas, ao contrário, procurar uma aproximação possível, no sentido de buscar um diálogo entre as áreas para aprofundar a pesquisa e o ensino de Dança. Isto é, ao invés de acentuar uma divisão, buscar somar forças com os demais colegas professores que trabalham com Dança, uma vez que a partir de momentos de troca e de conflito, de divergência de ideia, podem resultar interessantes ideias, dúvidas, questionamentos. Este processo pode ser produtivo, provocador, inusitado.

Com o passar do tempo, percebemos que há certa expectativa das outras áreas que também trabalham com Dança, como a Educação Física e a Pedagogia, por exemplo, em dialogar e compreender como a área de Dança trabalha a dança, por mais redundante que isto possa ser. Ou seja, abrir-se ao diálogo sensível e

DUARTE, Gustavo De Oliveira; CASTRO, Daniela Llopart; SILVA, Daniela Grieco Nascimento e. Dança no contexto escolar: antigas e novas questões. Revista da FUNDARTE. Montenegro, p.01-13, ano 21 , no 45, junho de 2021.

Disponível em: http://.seer.fundarte.rs.gov.br/index.php/revistadafundarte/index> 30 de junho de 2021. 


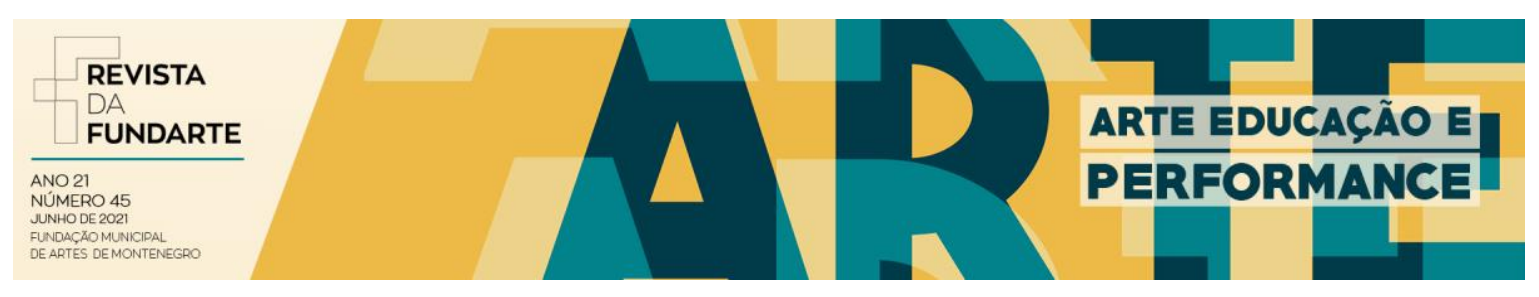

compartilhar nossos processos criativos, os estudos de movimentos e de processos de construção de composições coreográficas pode ser um caminho muito produtivo, tanto de demarcação e legitimidade do território da Dança, quanto de formação de público. O resultado pode ser surpreendente. A seguir buscamos apresentar algumas experiências de trabalho com Dança, a partir do diálogo com outras áreas e do trabalho que acompanhamos, a partir do PIBID Dança.

\section{Experiências do PIBID Dança: UFPel e UFSM}

O Programa Institucional de Bolsas de Iniciação à Docência (PIBID) é uma política do Ministério da Educação e da Coordenação de Aperfeiçoamento de Pessoal de Nível Superior (Capes), que visa atuar na qualificação da Educação Básica e na formação de Professores. Tivemos a grata oportunidade de participar do PIBID Dança da Universidade Federal de Pelotas (UFPel) em de 2012 a 2013 e, de 2014 a 2017, no PIBID Dança da Universidade Federal de Santa Maria (UFSM), ambas no contexto gaúcho, no Rio Grande do Sul. Sem sombra de dúvida, foram duas experiências extremamente gratificantes em nossa trajetória profissional, uma vez que interagimos com alunos, não só do Curso de Dança como de outras Licenciaturas, além de professores e diretores das Escolas parceiras. Diferentes Escolas, diferentes realidades, diferentes desafios, diferentes emoções.

De uma maneira geral, as ações do PIBID Dança desdobram-se em conhecer o contexto escolar e o processo da docência no contexto escolar. Antes da docência em Dança, propriamente dita, os alunos pibidianos realizaram uma pesquisa diagnóstica e um grande levantamento de dados e informações sobre o contexto escolar, sobre o cotidiano de seus professores por meio das limitações e das possibilidades de cada espaço. Aliado ao conhecimento das Escolas, os/as pibidianos/as realizaram Seminários de estudo sobre temáticas transversais à prática pedagógica a partir de temas Transversais como Meio Ambiente, Ética, Direitos Humanos, entre outros, a fim de instrumentalizar os futuros professores para a docência em Dança. Além de planejar e atuar em aulas e ações de Dança, dentro ou fora do Currículo Escolar, o PIBID também buscou atuar em ações e projetos

DUARTE, Gustavo De Oliveira; CASTRO, Daniela Llopart; SILVA, Daniela Grieco Nascimento e. Dança no contexto escolar: antigas e novas questões. Revista da FUNDARTE. Montenegro, p.01-13, ano $21, \mathrm{n}^{\circ}$ 45, junho de 2021.

Disponível em: http://.seer.fundarte.rs.gov.br/index.php/revistadafundarte/index> 30 de junho de 2021. 


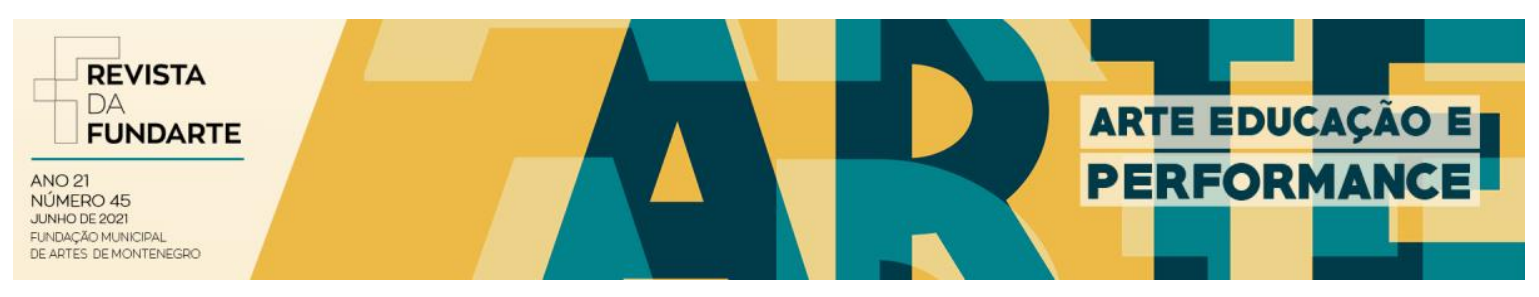

interdisciplinares com as demais áreas do conhecimento, que também fazem parte da proposta do PIBID.

Sobre as experiências acerca do ensino de Dança, a questão que mais nos chamou a atenção foi a transformação dos acadêmicos do Curso de Dança no enfrentamento e na preparação para a sala de aula. De alunos inseguros e desconfiados a sujeitos comprometidos e interessados em fazer o seu melhor, de acordo com as possibilidades de cada turm. Cada planejamento e reflexão de aula eram discutidos e problematizados no grupo, sempre com a presença da figura do/a Supervisor/a, o/a professor/a titular da Escola, que também fazia parte da proposta do PIBID Dança. Destacamos, a seguir, algumas destas ações: improvisação a partir do conhecimento do próprio corpo: dobrar, torcer, esticar, a partir dos estudos de Rudolf Laban (RENGEL, 2008); Dança a partir dos movimentos do cotidiano e da movimentação (re)conhecida do intervalo/recreio; Dança e cultura hip hop, personagens e curiosidades da História da Dança; Pesquisa em Dança - Folclore a partir do Subprojeto Feira de Etnias; Dança e Fotografia: olhares inusitados da Escola; Dança e a questão do Lixo: reciclar, separar, misturar; Dança e Africanidades; Dança e sexualidade(s); Dança, férias e viagens; Dança e Alfabeto: escrever em Dança, Dança e Literatura.

$\mathrm{Na}$ Universidade Federal de Pelotas (UFPel) tivemos a oportunidade de pesquisar dentro da Cultura urbana, o Movimento hip hop em uma Escola do Ensino Médio. Os pibidianos da Dança organizaram passeios e saídas em diferentes lugares da cidade coletando diversas imagens grafitadas, bem como palavras e frases escritas em praças, monumentos e muros. Tais materiais serviram como base e disparador para trabalhos de improvisação, trazidos para o corpo dos alunos da Escola. Além disso, eles também interagiram com dançarinos de um grupo de Dança de rua da cidade de Pelotas e um artista visual, que fez uma interação em um dos muros da Escola. Percebemos, além do interesse dos alunos, a curiosidade em pesquisar o tema e seus desdobramentos. Interagir com adolescentes, a partir de seus desejos e de suas vontades e críticas, foi o caminho escolhido neste trabalho, onde a temática foi construída e deliberada junto e com a turma.

DUARTE, Gustavo De Oliveira; CASTRO, Daniela Llopart; SILVA, Daniela Grieco Nascimento e. Dança no contexto escolar: antigas e novas questões. Revista da FUNDARTE. Montenegro, p.01-13, ano 21 , no 45, junho de 2021.

Disponível em: http://.seer.fundarte.rs.gov.br/index.php/revistadafundarte/index> 30 de junho de 2021. 


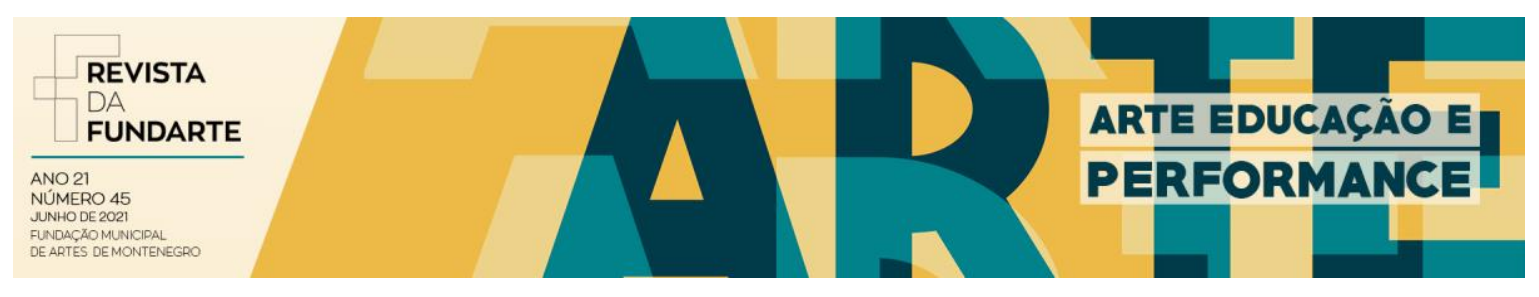

Já na Universidade Federal de Santa Maria (UFSM) destacamos um trabalho que se realizou a partir do diálogo entre as áreas de Música e Dança. Foram vários encontros entre os grupos de pibidianos das duas áreas, até que um tema despertou afinidades e desafios: o folclore gaúcho. A partir do eixo "Raízes e Asas" estudamos as danças do "Bugio" e do "Chamamé" (oriundas do Folclore Gaúcho) - histórico, características e possibilidades de movimento. Este desafio de planejar e ministrar uma oficina no Seminário Institucional do PIBID UFSM foi muito produtivo, pois tivemos participação dos demais acadêmicos pibidianos de outras áreas. No primeiro momento, depois da contextualização das duas danças orientamos os passos e gestualidades características do Bugio e do Chamamé, com o grupo do PIBID Música "tocando ao vivo" - foi uma experiência única, potente, marcante.

No segundo momento, após a experimentação e vivência dos passos de maneira individual e em pares e/ou duplas, trabalhamos com improvisação e desconstrução da movimentação estudada, no sentido de permitir maior expressividade e possibilidades de criação de movimentos a partir da sensibilidade de cada participante. Desta forma, depois das "Raízes", buscamos ir em direção às "Asas". A ideia é circular com esta Oficina nas Escolas parceiras do PIBID UFSM, as quais já mantemos contato, de modo a ampliar e compartilhar a proposta com crianças e adolescentes.

Outra ação relevante que conseguimos realizar na cidade de Santa Maria, após três anos de atuação em duas Escolas de bairros diferentes e com diferentes realidades, foi a sistematização de nossas atividades para o ensino de Dança em um livro chamado: "Qual é a sua Dança?: Dança para crianças e Adolescentes" (ANTUNES \& DUARTE, 2017). Inspirados em autores que tratam das interfaces entre Dança e Educação (LABAN, 1978; 1990), MARQUES, 1999: 2012), STRAZZACAPPA, 2006; RENGEL, 2008) sistematizamos um livro sobre metodologia de ensino de Dança, para crianças e adolescentes, a partir de nossa experiência na cidade de Santa Maria/RS, cidade de médio porte do interior gaúcho. O livro foi dividido, didaticamente em quatro eixos: 1) Consciência Corporal, 2) Fatores do Movimento, 3) Paisagens Sonoras e 4) Criação e Composição.

DUARTE, Gustavo De Oliveira; CASTRO, Daniela Llopart; SILVA, Daniela Grieco Nascimento e. Dança no contexto escolar: antigas e novas questões. Revista da FUNDARTE. Montenegro, p.01-13, ano 21 , no 45, junho de 2021.

Disponível em: http://.seer.fundarte.rs.gov.br/index.php/revistadafundarte/index> 30 de junho de 2021. 


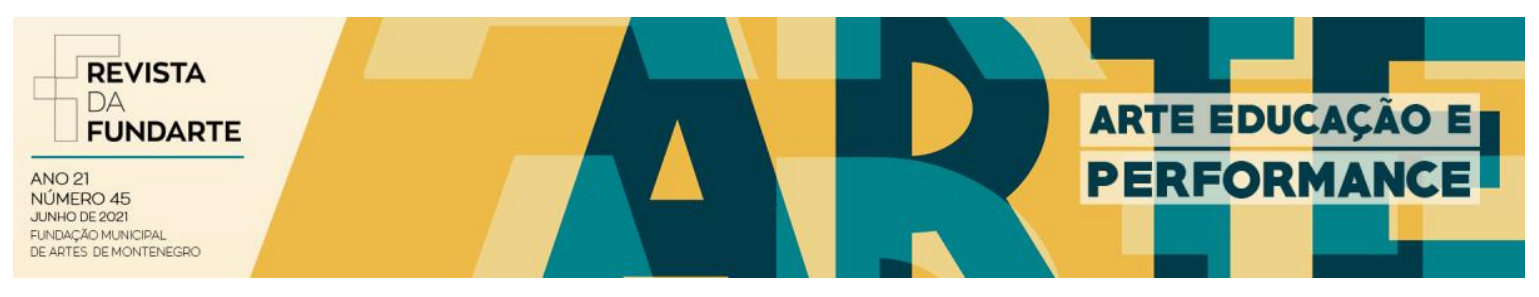

Compreendemos os quatro eixos como interdependentes e interconectados. Começamos pela consciência corporal pois, a partir dela, se desdobram os demais. Trata da ênfase do/no próprio corpo vivo, que se movimenta, que dança, ou seja, os diferentes corpos que buscam compreender sua própria corporeidade, sua subjetividade. Conhecer a si mesmo, a partir da inter-relação com as dimensões biológica, psicológica e social (afetiva, espiritual) é primordial para um trabalho de qualidade em dança, sobretudo no contexto escolar. O segundo eixo é totalmente inspirado nos estudos de Rudolph Laban (LABAN, 1978;1990): espaço, tempo, peso e fluência. Paisagens Sonoras refere-se, especificamente, aos ritmos interno e externo, que afetam os sujeitos que se movimentam, que inspiram e orientam o dançar: suas ênfases, variações, desdobramentos e invenções (im)possíveis. A partir deste eixo, é possível planejar atividades tanto de configuração mais "concreta" de educação rítmica e de diferentes estilos musicais e códigos de Dança (passos e gestualidades já conhecidos), como outras ações que propiciem a experimentação e criação de sons, ruídos, cenários sonoros mais abrangentes. Aconselhamos que o quarto eixo de criação e composição seja um desdobramento dos anteriores, visto a complexidade do mesmo. Este eixo propõe atividades relacionadas aos processos criativos e interpretativos e de códigos de Dança específicos, sejam eles tradicionais ou contemporâneos. Criar, imitar, brincar, ressignificar, inventar, (re)organizar, (des)estabilizar, provocar...enfim. Corpo, tempo, espaço, objetos, luz, entre outros podem e devem compor diferentes e criativas cenas dançantes, performances, coreografias.

Para Corrêa (2014), a contemporaneidade de uma proposta em Dança revela-se em determinadas atitudes e procedimentos que objetivam transformações evidenciadas no movimento artístico do tempo presente. Nesta linha de pensamento pode-se estabelecer uma relação direta entre o que acontece no mundo fora do ambiente escolar e a sala de aula. Não existe separação, ou seja, é fundamental que a aula de Dança seja um espaço de inquietação e questionamentos, onde promova-se a construção de um conhecimento conectado com a modernidade. "Afinal, os artistas se relacionam com eventos e questões que os cercam, e

DUARTE, Gustavo De Oliveira; CASTRO, Daniela Llopart; SILVA, Daniela Grieco Nascimento e. Dança no contexto escolar: antigas e novas questões. Revista da FUNDARTE. Montenegro, p.01-13, ano 21 , no 45 , junho de 2021.

Disponível em: http://.seer.fundarte.rs.gov.br/index.php/revistadafundarte/index> 30 de junho de 2021. 


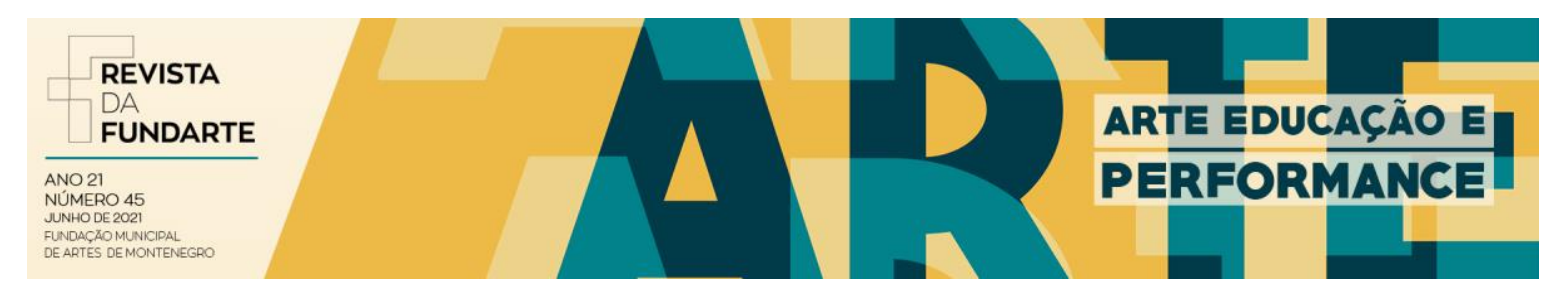

constroem maneiras de ver e representar que tem significados sociais". (HARVEY, 2008).

Ao finalizarmos este texto, ainda que em meio a um momento de crise financeira e política no qual nos encontramos, destacamos a importância do Programa do PIBID, tanto na formação inicial dos acadêmicos dos Cursos de Dança, quanto na formação continuada dos professores parceiros das Escolas.

O ensino de Dança, entre velhas e novas questões, segue se reinventando, resistindo, ao buscar fundamentar ainda mais sua importância no contexto escolar, de modo a contribuir na formação dos alunos, de construir modos de ver, de ser e de estar no mundo a partir da educação de sua sensibilidade. Por uma docência artista. Dancemos!

\section{Referências:}

BARBOSA, Ane Mae. Abordagem triangular no ensino das artes e cultura visual. São Paulo: Cortez, 2010.

BARRETO, Debora. Dança... Ensino, sentidos e possibilidades na escola. Campinas, SP: Autores Associados, 2005.

CORRÊA, Josiane Franken. Dança na educação básica: apropriações de práticas contemporâneas no ensino de dança. IN: Revista brasileira de estudos da presença, Porto Alegre, vol.4, n.3, p. 509-526, set/dez 2014.

DUARTE, Gustavo de Oliveira. "Escola-palco": por uma Educação Estética do Movimento Humano. IN: Arte na Escola: diálogos interdisciplinares - Ursula Rosa da Silva (org.). Pelotas: Editora Cidade Universitária, 2011.

. O Dançar na Educação Física Escolar: a experiência Estética no Movimento Humano. IN: Revista Educação, v.32 - N.1, p.241-254. Universidade Federal de Santa Maria/RS, 2003.

FElJÓ, Marcia Gonzales. A Dança como conteúdo integrante da Educação Física enquanto corporificação do mundo sensível. 1996. Dissertação (Mestrado). Universidade Federal de Santa Maria, Santa Maria/RS.

HASELBACH, Barbara. Dança, improvisação e movimento. Ed. Ao Livro Técnico, 1998.

HARVEY, David. A condição pós moderna. São Paulo: Loyola, 2008.

DUARTE, Gustavo De Oliveira; CASTRO, Daniela Llopart; SILVA, Daniela Grieco Nascimento e. Dança no contexto escolar: antigas e novas questões. Revista da FUNDARTE. Montenegro, p.01-13, ano 21 , no 45, junho de 2021.

Disponível em: http://.seer.fundarte.rs.gov.br/index.php/revistadafundarte/index> 30 de junho de 2021. 


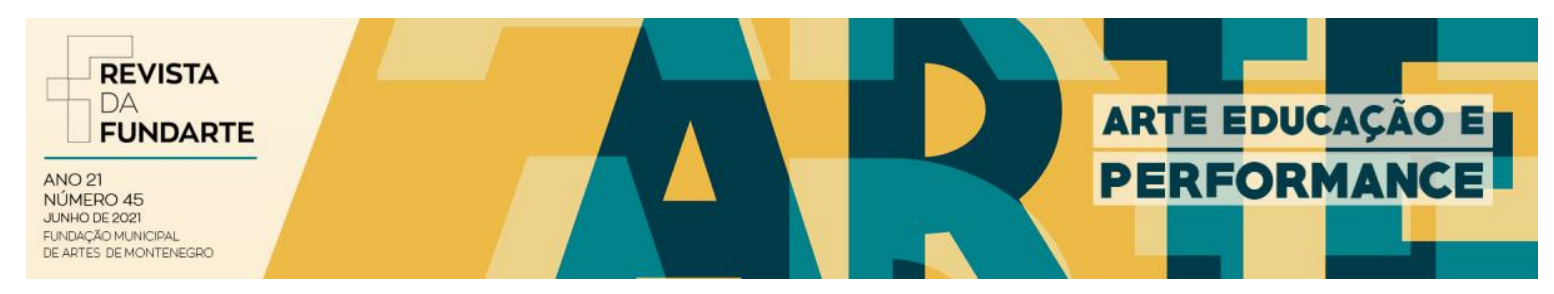

ICLE, Gilberto. Três tecnologias de subjetivação para pensar o ensino de dança na escola. IN: Educação Temática Digital, Campinas, vol.18, n.3, p. 628-650, jul/set 2016.

MARQUES, Isabel. Linguagem da Dança: Arte e Ensino. São Paulo: Digitexto, 2010.

MIRANDA, M. L. A dança como conteúdo específico nos cursos de educação física e como área de estudo no ensino superior. IN: Revista Paulista De Educação Física, 8(2), 3-13. 1994.

PACHECO, A. J. Educação Física e Dança: uma análise bibliográfica. IN: Pensar a Prática, n. 2, p. 156-171, 2006.

RENGEL, Lenira. Os Temas de Movimento de Rudolf Laban (I-II-III-IV-V-VI-VII-VIII): modos de aplicação e referências. São Paulo: Annablume, 2008.

STRAZZACAPPA. Marcia. Entre a Arte e a Docência: a Formação do Artista da Dança. Campinas, SP: Papirus, 2006.

DUARTE, Gustavo De Oliveira; CASTRO, Daniela Llopart; SILVA, Daniela Grieco Nascimento e. Dança no contexto escolar: antigas e novas questões. Revista da FUNDARTE. Montenegro, p.01-13, ano 21, no 45, junho de 2021.

Disponível em: http://.seer.fundarte.rs.gov.br/index.php/revistadafundarte/index> 30 de junho de 2021. 